\title{
Re: Activated Omentum Slows Progression of CKD
}

\author{
Garcia-Gomez I1, Pancholi N², Patel J2, Gudehithlu KP3, Sethupathi P2, Hart P4, Dunea G1, Arruda JA5, Singh AK6 \\ 1 John H. Stroger Jr. Hospital of Cook County, Clinic of Nephrology; Hektoen Institute of Medicine; University of Illinois Medical Center at \\ Chicago, Department of Medicine, Division of Nephrology, Chicago, Illinois, USA \\ 2Hektoen Institute of Medicine, Chicago, Illinois, USA \\ 3John H. Stroger Jr. Hospital of Cook County, Clinic of Nephrology, Chicago, Illinois, USA \\ 4John H. Stroger Jr. Hospital of Cook County, Clinic of Nephrology; Hektoen Institute of Medicine, Chicago, Illinois, USA \\ 5 John H. Stroger Jr. Hospital of Cook County, Clinic of Nephrology; Hektoen Institute of Medicine; University of Illinois Medical Center at \\ Chicago, Department of Medicine, Division of Nephrology; Jesse Brown Chicago Veterans Affairs Medical Center, Chicago, Illinois, USA \\ 6 John H. Stroger Jr. Hospital of Cook County, Clinic of Nephrology; Hektoen Institute of Medicine; University of Illinois Medical Center at \\ Chicago, Department of Medicine, Division of Nephrology, Chicago, Illinois, USA
}

J Am Soc Nephrol 2014;25:1270-81. doi: 10.1681/ASN.2013040387. Epub 2014 Mar 13.

\section{EDITORIAL COMMENT}

Perinephric fatty tissue has been commonly used for the purpose of stopping bleeding especially during partial nephrectomy or nephrorrhaphy. In this study the authors reported that the omentum could be used also for preserving the remnant kidney and preserving its function. Especially the omentum contains a large amount of stem cells. Stem cells show promise in the treatment of acute kidney injuries but do not survive for more than a few days after injection. The authors aimed to examine whether fusing the omentum to a subtotally nephrectomized kidney could slow the progression of chronic kidney disease. They used two groups of rats: an experimental group undergoing 5/6 nephrectomy only and a control group undergoing 5/6 nephrectomy and complete omentectomy. After 12 weeks, they examined both groups via biochemical and histological analyses and it was observed that experimental rats had lower plasma creatinine levels; less glomerulosclerosis, tubulointerstitial injury and extracellular matrix, and reduced thickening of basement membranes compared with controls. A fusion zone formed between the injured kidney and the omentum contained abundant stem cells expressing stem cell antigen-1, Wilms' tumor-1, and CD34. Kidney extracts from experimental rats showed increases in expression levels of growth factors involved in renal repair. These results suggest that contact between the omentum and injured kidney slows the progression of chronic kidney disease in the remnant organ. These results should be remembered during the repair of injured kidney or partial nephrectomy.

Fehmi Narter, MD, PhD

बCopyright 2018 by the Association of Urological Surgery / Journal of Urological Surgery published by Galenos Publishing House. 